\title{
Sağlık Hizmetleri Meslek Yüksekokulu Öğrencilerinin Uygulamalı Derslere İlişkin Görüşleri*
}

\author{
Health Services Vocational School Students' Opinions About Applied Courses*
}

\author{
Ayfer YÜKSEL
}

öz

Bu araştırmanın amacı; Sağlık Hizmetleri Meslek Yüksekokulu (SHMYO) öğrencilerinin uygulamalı derslere ilişkin görüş ve düşüncelerini betimlemektir. Araştırmanın evrenini 2017-18 eğitim öğretim yılı bahar döneminde bir vakıf üniversitesinin SHMYO'na devam eden ikinci sınıf öğrencileri $(\mathrm{N}=67)$ oluşturmaktadır. Örneklem ilgili evrenden kolaylıkla bulabileni örnekleme yöntemi kullanılarak iki program olarak belirlenmiştir. Örneklemi oluşturan öğrencilerin \% 70’i (n=47) kadın, \% 30’u (n=20) erkektir.

Araştırmada veri toplama aracı olarak araştırmacı tarafından geliştirilen Kişisel Bilgi Formu (KBF) ve Öğrenci Görüş Anketi (ÖGA) kullanılmıştır. KBF yedi, ÖGA ise 13 sorudan oluşmaktadır. Araştırma sonuçlarına göre öğrencilerin eğitim gördükleri programı tercih etme nedenleri ve uygulamalı derslere ilişkin görüşlerinin farklılaştığ bulunmuştur. Örneğin öğrencilerin \% 36's1 "sevdiği için", \% 28'i “kısa sürede iş sahibi olabilmek için", \% 15'i de "sınav sisteminden dolayı" şuan eğitim gördükleri programı tercih etmiş etmişlerdir. Öğrencilerin \% 66's1 "uygulama öncesinde uygulamanın tecrübe kazandıracağını" düşünürken, uygulamanın sonrasında öğrencilerin \% 43'ünün bu düşüncesi değişmiş ve uygulamanın olumlu katkısı olduğunu düşünenlerin oranı \% 52 olarak bulunmuştur. Bu sonuç, uygulamalarda ögrencilerin beklentilerinin tam anlamıyla karşılanamadığ1 şeklinde yorumlanabilir. Uygulamalı dersleri daha etkin hale getirmek için sizce nasıl bir yöntem kullanılmalıdır? sorusuna ögrencilerin \% 51'i “teknik donanım vb. daha iyi olmalı" derken; yalnızca \% 16's1 "mevcut sistemin iyi olduğunu" belirtmişlerdir.

Elde edilen bulgular, literatüre dayalı olarak tartışılmış ve önerilerde bulunulmuştur.

Anahtar Kelimeler: SHMYO öğrencileri, öğrenci görüşü, uygulamalı ders

* Uluslararası Kültür Bilim Kongresinde-Ankara, Ufuk Üniversitesi, 3-5 Mayıs 2018 ‘de sözlü bildiri olarak yayınlanmıştır.

Ayfer YÜKSEL (ه)

Ufuk Üniversitesi Sağllk Hizmetleri Meslek Yüksekokulu Öğretim Üyesi, Balgat, Ankara.

e-posta:drayferercan@yahoo.com

\begin{abstract}
The purpose of this research is to describe the opinions and thoughts of students at the Health Services Vocational School related to applied courses. The sample was determined as two programs using the convenience sampling method in the relevant phase. Participants were 67 associate degree program students at a private university, $70 \%$ male, $30 \%$ female.

Personal İnformation Form and Student Opinion Survey were used as data collection tool. Results of the research, the reasons why students choose the program they are studying and their opinions about practical courses differ. For example students say they prefer the program because they like $36 \%$ of the students, $28 \%$ prefer the program to be a short-term business owner and $15 \%$ prefer the program because of the examination system. $66 \%$ of the students thought that the practice would gain experience before the practice, while the proportion of those who thought that $43 \%$ of the students thought that this thought had changed and contributed to the practice was found to be $52 \%$. This result can be interpreted as the fact that the expectations of the students cannot be fully met in practice. In order to make practical lessons more effective, what kind of method should be applied to you? $51 \%$ of the students say that they should be good at technical equipment etc.; only $16 \%$ of the students say that the current system is good.

The findings were discussed and suggested based on the literature. Keywords: Health services vocational school students, student views, course practice
\end{abstract}

\section{GíRiş}

Meslek Yüksek Okulları (MYO), üst düzeyde uygulayıcı meslek elemanı yetiştiren yükseköğretim kurumlarıdır. MYO'da iki yıl süreli eğitim verilmektedir. Mezun olma hakkı kazanan öğrencilere, bağlı bulunduğu üniversiteden ön lisans derecesinde diploma verilir. Teknik bölümlerden mezun olan öğrenciler tekniker unvanı kazanır. MYO orta öğretimden sonra eğitim veren genellikle bilgi üretmeyip temel bilgilerden yola çıkarak çeşitli kurum ya da kuruluşların, özel sektörlerin kalifiye eleman ihtiyacını 
karşılamaya çalışan okullardır (1). MYO'nın açılmasındaki temel amaç; sanayinin ihtiyacı olan ara kademe teknik elemanlarının öğretimini gerçekleştirmektir. Bu nedenle de mesleki uygulamalara ilişkin derslere daha ağırlıklı olarak yer verilmektedir.

Mesleki uygulama eğitimlerinde amaç, sadece öğrencilerin alanları ile ilgili deneyim kazanmaları değildir. Bunun yanında "düşünen, araştırabilen, sanatsal duyarlılığı olan, özgüvene sahip, girişimci" bir kitlenin yetiştirilmesi de amaçlanmaktadır (2).

Meslek yüksekokullarında bir taraftan öğrencilere teorik bilgiler verilirken diğer taraftan uygulamalı olarak pratik mesleki uygulama eğitimleri de verilmektedir. Yükseköğretim Kurumunun mesleki teknik eğitim bölgesi içindeki meslek yüksekokulları öğrencilerinin işyerlerindeki eğitim uygulama ve stajlarına ilişkin esas ve usuller hakkındaki yönetmeliğin ilk maddesinde amaç olarak, mesleki ve teknik eğitim bölgeleri içindeki meslek yüksekokullarında öğrenim gören öğrencilerinin öğrenim süreleri içinde kazandıkları teorik bilgi ve deneyimleri pekiştirmek, laboratuar ve atölye uygulamalarında edindikleri beceri ve deneyimleri geliştirmek, görev yapacakları iş yerlerindeki sorumluluklarını, ilişkileri organizasyon ve üretim sürecini ve yeni teknolojileri tanımalarını sağlamaktır (3).

Özellikle sağlık alanında kalifiye eleman ihtiyacını karşılayabilmek için açılmış olan, sağlık hizmetleri meslek yüksekokulları, hemşirelik meslek yüksekokulları, sağlık teknikerliği meslek yüksekokulları, vb. okullarda mesleki uygulama dönemleri çok önemlidir. Çünkü buralarda verilen uygulama dersleri ve eğitimleri ileride bir insanın hayatını kurtarabilmek ile kurtaramamak arasında ince bir çizgi gibidir. Hemşirelik meslek yüksekokullarında öğrenci öğrenimi için gerçek yaşam deneyimi sağlamak, yeni bilgi ve teknolojiyi denemek ve hemşirelik uygulamalarını geliştirmede çeşitli yollar bulmak için hemşirelik hizmetlerine her türlü ihtiyaç vardır (4).

Gallup'un 2014 yılında en az beş y1ldır iş yaşamında çalışan üniversite mezunlarıyla yaptığı geniş kapsamlı bir araştırma öğrencilerin okulda öğrendikleriyle ilgili staj yapmanın önemini göstermektedir. Bir milyondan fazla Amerikalı çalışan, öğrenci, eğitici ve işvereni kapsayan bir araştırmada iki önemli deneyimin ön plana çıktığı görülmüştür: Başarılı öğrenciler, onların tutkularıyla gerçekten ilgilenen bir ya da daha fazla öğretim elamanına sahip olan ve okulda öğrendikleri şeyleri uygulama firsatı buldukları bir staj yapan öğrencilerdir. Araştırma sonucu bu çalışanların işlerine daha bağlı olduklarını göstermektedir (5).

Meslek Yüksekokullarındaki uygulama derslerine ilişkin alan yazın incelendiğinde bazı araştırmalara ulaşılmıştır. Son on y1lda betimlenen sorunlar ve getirilen öneriler birbirine yakın görünmektedir. Bu bağlamda karşılaşılan sorunlarda fazla bir ilerleme kaydedildiğini söylemek mümkün değildir.

Ayrıca araştırmada öğrencilerin uygulamalı dersler ile ilgili sorunları belirlenerek bunlara çeşitli çözüm önerileri getirilmeye çalışılmıştır.

$\mathrm{Bu}$ araştırmanın uygulama dersi olan tüm öğrenci, öğretmen, öğretim elemanı ve eğitimcilere iyi bir rehber olacağı düşünülmektedir. Dolayısıyla, bu araştırmadan elde edilen bulgulardan hareketle; akademisyen ve eğitimcilerin, öğrencilerin uygulama sırasında saptanan sorunlarına daha fazla eğileceklerine inanılmaktadır.

Problem cümlesi: Sağlık Hizmetleri Meslek Yüksekokulu (SHMYO) öğrencilerinin uygulamalı derslere ilişkin görüş ve düşünceleri nelerdir?

Alt problemler: Problem cümlesine bağlı olarak, şu sorulara yanıt aranmıştır. Elektronörofizyoloji (ENF) ve İlk ve Acil Yardım (İAY) öğrencilerinin, eğitim gördükleri programı tercih etme nedenleri, yapılan uygulamaların teorik dersleri pekiştirme ve kavramada olumlu katk1 sağlayıp sağlamadığı, uygulama ders saatleri süresinin yeterli olup olmadığı, uygulama sirasında uygulama yapılan kurum tarafindan verilen uygulama eğitiminin yeterli olup olmadığı, uygulamalı dersleri daha etkin hale getirmek için nasıl bir yöntem uygulanması gerektiği ve uygulama yapılan kurumun teknik donanım açısından nasıl olduğu, hakkındaki düşünceleri nelerdir ?

\section{YÖNTEM}

Araştırma betimsel bir araştırmadır, tarama modeli deseni kullanılmıştır. Tarama modelleri, geçmişte ya da halen var olan bir durumu var olduğu şekliyle betimlemeyi amaçlayan araştırma yaklaşımlarıdır (6).

\section{Evren ve Örneklem}

Araştırmanın evrenini, 2017-2018 eğitim-öğretim yılı bahar döneminde bir vakıf üniversitesinin SHMYO'na devam eden ikinci sınıf öğrencileri (N=67) oluşturmaktadır. Araştırmada, araştırmacının yakın çevresinde bulunan, ulaşılması kolay 
ve araştırmaya katılmaya gönüllü bireyler ile çalışılan örneklem türü olarak tanımlanan kolaylıkla bulabileni örnekleme yöntemi kullanılmıştır $(7,8)$. Örneklem, evrenden kolaylıkla bulabileni örnekleme yöntemi kullanılarak iki program olarak belirlenmiştir (Elektronörofizyoloji $n=36$; İlk ve Acil Yardım $n=31$ ). Örneklemi oluşturan öğrencilerin $\%$ 70'i (n=47) kadın \% 30’u (n=20) erkektir. Katılımcıların yaş aralı̆̆1; \%70'i 20-21, \% 13'ü 22-23 yaş aralığındadır. Katılımcıların yaşamlarının çoğunluğunu geçirdikleri bölge \% 82 İç Anadolu, \% 6 Akdeniz, \% 5'er de Ege ve Karadeniz bölgesidir. Katılımcıların mezun oldukları lise türüne bakıldığında \% 43' ünün meslek lisesi, \% 52' sinin ise diğer lise mezunu olduğu görülmektedir.

\section{Verilerin toplanması ve çözümlenmesi}

Araştırmada iki adet veri toplama aracı kullanılmıştır. Bunlar araştırmacı tarafından geliştirilen Kişisel Bilgi Formu ve SHMYO öğrencilerinin uygulamalı derslere ilişkin görüşlerinin incelenmesi amacıyla geliştirilen Öğrenci Görüş Anketidir. Anket, araştırma katılımcılarının doldurduğu veri toplama araçlarıdır. Anketler katılımcıların fikir ve algılarını ölçer (9). KBF, yedi sorudan oluşmaktadır. Anket ise on iki kapalı uçlu soru ve bir açık uçlu soru olmak üzere toplam on üç sorudan oluşmaktadır. Literatüre, yarı yapılandırılmış veri toplama aracına ve odak grup toplantılarında elde edilen verilere dayalı olarak, ankete son şekli verilmiştir. Veri toplama aracının içerik geçerliği, Karasar'ın "Veri toplama aracinda bulunan maddelerin, ölçme amacına uygun olup olmadığı ölçülmek istenen alanı temsil edip etmediği sorunu ile ilgili olup, bu uzman görüşüne göre saptanır" (6) ifadesine göre sağlanmıştır. Bu kapsamda alandaki öğretim elemanları ile görüşülmüş ve onlardan gelen geri bildirimler sonrası veri toplama aracına son şekli verilmiştir. Ufuk Üniversitesi Sosyal ve Beşeri Bilimler Bilimsel Araştırma ve Yayın Etiği Kurulundan Etik kurul izni alınarak ölçme araçlarının uygulaması yapılmıştır. Verilerin çözümlenmesi ve değerlendirilmesinde frekans (f) ve yüzde (\%) hesaplanmıştır. İki süreksiz değişken arasında anlamlı bir ilişkinin olup olmadığı kay kare testi ile incelenmek istenmiştir. Testin kullanılması için hiçbir gözenekte beklenen değerin beşin altında olmaması ve beklenen değer beşten küçük olan gözenek sayısının \%20'nin altına düşmemesi gerekir. Araştırma katılımcılarının sayısından kaynaklanan bu sınırlılık nedeniyle, sadece tablo üzerinden frekans ve yüzde kullanılarak yorum yapılmaya çalışılmıştır. Verilerin yorumlanmasında bu sınırlılık dikkate alınmalıdır.

\section{BULGULAR}

Araştırmanın birinci alt problemi "Eğitim gördüğünüz programı tercih etme nedeniniz nedir?" şeklinde ifade edilmişti. Katılımcıların bu alt probleme ilişkin verdikleri cevaplar incelendiğinde, öğrencilerin \% 36's1 “sevdiği için" , \% 28'i "kısa sürede iş sahibi olabilmek için", \% 15 'i "sınav sisteminden dolayı" ve \% 6's1 "ailemin isteği”" nedeni ile programı tercih ettiğini belirtmekte, \% 10'u "diğer" seçeneğini işaretlemişlerdir. Bu dağılım; bizlere öğrencilerin yaklaşık 1/3 kadarının bölümlerini severek tercih ettiklerini göstermektedir.

"Uygulama yapmadan önce uygulamanın size tecrübe kazandıracağını düşünüyor muydunuz?" sorusu araştırmanın ikinci alt problemi olarak ifade edilmişti. Bu soruya ilişkin öğrencilerin görüşleri Tablo 1'de verilmektedir.

Tablo 1. Öğrencilerin "Uygulama yapmadan önce uygulamanın size tecrübe kazandıracağını düşünüyor muydunuz?” sorusuna ilişkin görüşlerinin dağılımı

\begin{tabular}{|l|l|l|l|l|}
\hline Program ad 1 & Evet & Kismen & Hayır & Toplam \\
N $(\%)$ & N $(\%)$ & N $(\%)$ & N $)$ \\
\hline İAY & $25(81)$ & $6(19)$ & $0(0)$ & $31(100)$ \\
\hline ENF & $19(53)$ & $12(33)$ & $5(4)$ & $36(100)$ \\
\hline TOPLAM & $44(66)$ & $18(26)$ & $5(8)$ & $67(100)$ \\
\hline
\end{tabular}

Tablo 1'de görüldüğü gibi öğrencilerin \% 66'sı bu soruya "evet", \% 27'si "kısmen", \% 8'i de "hayır" şeklinde cevap vermişlerdir. Öğrencilerin programlarına göre bu soruya verdikleri cevaplar incelendiğinde, İlk ve Acil Yardım (İAY) öğrencilerin \% 81'i bu soruya "evet", \% 19'u "kısmen" şeklinde cevap vermişlerdir. Buna karşı1lı, Elektronörofizyoloji (ENF) programı öğrencilerinin \% 53'ü bu soruya "evet", \% 33'ü "kismen" ve \% 14'ü de "hayır" şeklinde görüş belirtmiştir.

Araştırmanın üçüncü alt problemi "Uygulama yaptıktan sonra uygulamanın size tecrübe kazandıracağı düşüncenizde değişiklik oldu mu?" şeklinde ifade edilmişti. Bu soruya ilişkin öğrencilerin görüşleri Tablo 2'de verilmektedir.

Tablo 2. Öğrencilerin "Uygulama yaptıktan sonra uygulamanın size tecrübe kazandıracağı düşüncenizde değişiklik oldu mu?” sorusuna ilişkin görüşlerinin dağılımı

\begin{tabular}{|l|l|l|l|l|}
\hline Program ad 1 & Evet & Kismen & Hayır & Toplam \\
& $\mathrm{N}(\%)$ & $\mathrm{N}(\%)$ & $\mathrm{N}(\%)$ & $\mathrm{N}(\%)$ \\
\hline İAY & $18(58)$ & $5(16)$ & $8(29)$ & $31(100)$ \\
\hline ENF & $11(31)$ & $13(36)$ & $12(33)$ & $36(100)$ \\
\hline TOPLAM & $29(43)$ & $18(27)$ & $20(30)$ & $67(100)$ \\
\hline
\end{tabular}


Tablo 2 incelendiğinde, katılımcıların \% 43'ü "evet”, \% 27'si "kısmen", \% 30'u "hayır" şeklinde cevap vermişlerdir. Öğrencilerin programlarına göre bu soruya verdikleri cevaplar incelendiğinde, İAY öğrencilerin \% 58'i bu soruya "evet", \% 16's1 "kısmen", \% 29'u ise "hayır" şeklinde cevap vermişlerdir. Buna karşılık, ENF programı öğrencilerinin $\% 31$ 'i bu soruya "evet", \% 36's1 "kısmen" ve \% 33'ü de "hayır" şeklinde görüş belirtmiştir.

Araştırmanın dördüncü alt problemi; "Yaptığınız uygulamalar, teorik derslerinizi pekiştirme ve kavramanızda olumlu katkı sağladı mı?" şeklinde ifade edilmişti. Bu soruya ilişkin öğrencilerin görüşleri Tablo 3'de verilmektedir.

Tablo 3. Öğrencilerin "Yaptığınız uygulamalar, teorik derslerinizi pekiştirme ve kavramanızda olumlu katkı sağladı mı?” sorusuna ilişkin görüşlerinin dağılımı

\begin{tabular}{|l|l|l|l|l|}
\hline Program adı & $\begin{array}{l}\text { Evet } \\
\mathrm{N}(\%)\end{array}$ & $\begin{array}{l}\text { Kismen } \\
\mathrm{N}(\%)\end{array}$ & $\begin{array}{l}\text { Hayır } \\
\mathrm{N}(\%)\end{array}$ & $\begin{array}{l}\text { Toplam } \\
\mathrm{N}(\%)\end{array}$ \\
\hline İAY & $18(58)$ & $12(39)$ & $1(3)$ & $31(100)$ \\
\hline ENF & $17(47)$ & $15(42)$ & $4(11)$ & $36(100)$ \\
\hline TOPLAM & $35(52)$ & $27(40)$ & $5(8)$ & $67(100)$ \\
\hline
\end{tabular}

Araştırmaya katılan öğrencilerin \% 52'si bu soruya "evet", \% 40'1 “kısmen”, \% 8'i "hayır" şeklinde cevap vermişlerdir. Öğrencilerin kayıtlı oldukları programa göre bu soruya verdikleri cevaplar incelendiğinde, İAY öğrencilerin \% 58'i bu soruya "evet", \% 39'u "kismen" ve \% 3'ü ise "hayır" şeklinde cevap vermiş̧lerdir. Buna karşlık, ENF programı öğrencilerinin \% 47'si bu soruya "evet”, \% 42'i "kısmen" ve \% 11'i de "hayır" şeklinde görüş belirtmiştir.

$\mathrm{Bu}$ üç soruya (ikinci, üçüncü ve dördüncü alt problem soruları) verilen cevap ile öğrencilerin uygulamadan önce ve sonraki görüşleri karşılaştırılmıştır. Buna göre öğrencilerin \% 66'sı uygulama öncesinde uygulamanın tecrübe kazandıracağını düşünürken; Uygulamanın sonrasında, öğrencilerin \% 43'ünün bu düşüncesi değişmiş ve uygulamanın olumlu katkısı olduğunu düşünenlerin oranı \% 52'olarak bulunmuştur. Bu sonuç, uygulamalarda öğrencilerin beklentilerinin tam anlamıyla karşılanamadığ 1 şeklinde yorumlanabilir.

“Uygulama ders saatleri süresi sizce yeterli miydi?" sorusu araştırmada cevaplandırılması gereken beşinci alt problem olarak ifade edilmişti. Araştırmaya katılan öğrencilerin \% 33'ü bu soruya "evet yeterliydi”, \% 42'si "kismen yeterliydi" ve \% 25'i "hayır yeterli değildi” şeklinde görüş belirtmektedir.
Araştırmanın altıncı alt problemi; "Uygulama sırasında uygulama yaptığınız kurum tarafından size verilen uygulama eğitiminin yeterli olduğunu düşünüyor musunuz?" şeklinde ifade edilmişti. Öğrencilerin \% 34'ü bu soruya "evet", \% 36'sı kısmen "yeterli", \% 30'u "yetersiz" şeklinde görüş belirtmiştir.

Araştırmanın cevap aradığ yedinci soru; "Mezun olduktan sonra uygulama yaptığınız kurumda çalışmak ister misiniz?" şeklinde olup; öğrencilerin \% 36's1 “evet”, \% 39'u "kararsızım", \% 25'i "hayır" şeklinde görüş belirtmişlerdir.

"Sizce uygulama neyi ifade ediyor?" sorusu araştırmanın sekizinci alt problemi olup; öğrencilerin $\% 75$ 'i alınan “teorik bilgileri pratik ile pekiştirme”, \% 19'u "mesleği yakından tanıma", \% 5'i "sadece mezun olmak için okul programının gereğini yerine getirmek", ve \% 2'si de "diğer" olarak görüş belirtmişlerdir.

"Uygulama yaptığınız kurumu teknik donanım açısından nasıl değerlendirirsiniz?" sorusu araştırmanın dokuzuncu alt problemi olup; öğrencilerin \% 22'si “yeterli” \% 49'u "kısmen yeterli" \% 28'i ise "yetersiz" şeklinde görüş belirtmişlerdir.

"Uygulamaları daha etkin hale getirmek için sizce nasıl bir yöntem uygulanmalıdır?" sorusu araştırmanın onuncu alt problemi olup; öğrencilerin \% 51'i “teknik donanım vb. daha iyi olmalı", \% 15 'i "uygulama ders saatleri daha çok olmalı", \% 8'i "devamsızlık vb. daha sıkı denetlenmeli" şeklinde cevap verirken sadece \% 16's1 "mevcut sistemin iyi olduğunu" ifade etmektedirler.

\section{TARTIŞMA VE SONUÇ}

Eraslan(10) 47 adayla yaptığı çalışmada adayların uygulama için yeteri kadar firsat bulamadıklarını, yeterince dönüt alamadıklarını ve teorik ile pratiği ilişkilendiremediklerini ortaya koymuştur. Paydaşların koordineli bir şekilde çalışması; öğretmenlerin iyi yetişmiş ve istekliler arasından seçilmesi; adayların derse karşı motivasyonlarının arttırılması gerektiğini belirtmiştir. Bizim çalışmamızda da uygulamalar öncesi uygulamaların teorik dersleri pekiştirmeye katkısı olacağını düşünenlerin oranı uygulama dersleri sonrasında düşmüştür. Uygulamaların öğrencilerin istediği gibi teknik donanımdaki yetersizliklerin giderilerek daha etkin hale getirilebileceği öngörülmektedir.

Araştırma bulguları, Gökdoğan ve Sarıgöz (1); Hançer Aydemir (11) ve Tuygar (12)'ın bulguları ile karşılaştırılarak tartışılmıştır. Katılımcı öğrenciler mesleki 
uygulama süresinin kısa olmasından yakınmaktadır. Bunun sebebi öğrenciler tek başlarına mesleğe atılmadan önce mesleki uygulama döneminde meslekte karşılaşacağı ve karşılaşabileceği tüm problemleri görerek daha önceden deneyim kazanmak istemelerindendir. Aslında meslek yüksekokulları teorik ve pratik olarak meslek derslerinin verildiği yerlerdir. Bu nedenle öğrenciler okullar tarafından yaz dönemleri de dâhil olmak üzere öğrencileri daha fazla mesleki uygulamaya görevlendirilmelidirler (1). Bu araştırmada ise öğrencilerin sadece \% 25 'i uygulama ders saatlerinin süresini yetersiz görmektedir.

Hançer Aydemir tarafından (11) yapılan çalışmada, öğrencilerin büyük bir bölümü ( $\%$ 63) staj süresinin yeterli olduğunu, stajları daha etkin hale getirebilmek için denetim yapılmasının gerekli olduğunu belirtmişlerdir (\% 45). Bizim çalışmamızda uygulamalı derslerin daha etkin hale getirilmesi için uygulama ders saatlerinin artırılmasını isteyenler \% 15 iken öğrencilerin \% 51'i uygulama yapılan birimdeki teknik donanımın daha iyi hale getirilmesi gerektiğini düşünmektedirler.

Tuygar'ın yaptığı araştırmada, paramedik programı öğrencilerinin yaz stajı ile ilgili görüşlerinin olumlu yönde olduğu, bir işe yerleştiklerinde mesleki uygulamalarda edindikleri tecrübe, bilgi ve deneyimlerin işlerine çok yarayacağını ve kendilerini daha bilgili ve bilinçli hale getireceğini düşündükleri gibi sonuçlara ulaşılmıştır (12). $\mathrm{Bu}$ çalışmada ise uygulama öncesi öğrencilerimizin \% 66's1 uygulamanın tecrübe kazandıracağını düşünürken; uygulama dersleri sonrası öğrencilerin \% 43'ünün düşüncesi değişmiş ve uygulamanın olumlu katkısı olduğunu düşünenlerin oranı $\% 52$ olarak bulunmuştur. Ayrıca; uygulama eğitiminin yeterli olup olmadığı sorusuna katılımcıların \% 34 yeterli, \% 36'sı kısmen yeterli, \% 30'u ise yetersiz olduğu şeklinde cevap vermişlerdir.

\section{SONUÇ}

Araştırmaya katılan öğrencilerin \%36's1 bölümlerini severek seçmektedirler. Her dört öğrenciden biri uygulama ders saatleri süresini yeterli bulmamaktadır. Yaklaşık her üç öğrenciden biri verilen uygulama eğitimini yetersiz bulmaktadır. Araştırmaya katılan iki öğrenciden biri uygulamaların teorik dersleri pekiştirme ve kavramada olumlu katkı sağladığını düşünmekte, ancak on öğrenciden yaklaşı ikisi uygulamalı derslerle ilgili mevcut sistemi iyi bulmaktadır.
Araştırmaya katılan her iki öğrenciden biri, uygulamalı dersleri daha etkin hale getirmek için(\%51)teknik donanımın daha iyi hale getirilmesi gerektiğini düşünmektedir.

\section{ÖNERÍLER}

Bu araştırmada; öğrencilerin \% 30'u uygulamalı derslerdeki eğitimlerin yetersiz olduğunu düşünmektedirler. $\mathrm{Bu}$ durum; uygulama eğitimlerinin öğrenci memnuniyeti ve beklentileri de dikkate alınarak değerlendirilmeleri ve bu bağlamda eksikliklerin saptanarak gerekli düzenlemelerin yapılmasının yararlı olacağı kanısındayız. Araştırma sonuçlarına göre; SHMYO'da uygulamalı derslerle ilgili var olan mevcut sistemin revize edilip geliştirilmesi, uygulama ders saatlerinin artırılması, uygulama yapılan yerlerdeki teknik donanım vb. konularda gerekli düzenlemeler yapılması, önerilebilir. Ayrıca ortaöğretim kurumlarında öğrencilerin kendilerini tanımaları ve meslek tercihleri yönünden sağlıklı kararlar vermesine yönelik hizmetlerinin etkili hale getirilmesi önerilebilir.

\section{KAYNAKLAR}

1. Gökdoğan O, Sarıgöz, O. Meslek yüksekokulu öğrencilerinin 'mesleki uygulama dersi' ile ilgili görüşlerinin değerlendirilmesi. Batman Üniversitesi Yaşam Bilimleri Dergisi, 1 (1), 1091-1100, 2012. Retrieved from http:// dergipark.gov.tr/buyasambid/issue/ 29824/ 320956

2. Binici H.,Arı N. Mesleki ve teknik eğitimde arayışlar, Gazi Üniversitesi, Gazi Eğitim Fakültesi Dergisi, 2004; 24(3):383396.

3. T.C. Resmi Gazete, Mesleki teknik eğitim bölgesi içindeki meslek yüksekokulu öğrencilerinin işyerlerindeki eğitim, uygulama ve stajlarına ilişkin esas ve usuller hakkında yönetmelik, 22 Mayıs 2002 Tarih ve 24762 Sayılı Resmi Gazete.

4. Gümral N.,Coşar ,F. Ebelik ve hemşirelik son sınıf öğrencilerinin okul-hastane işbirliği ile ilgili görüşlerinin değerlendirilmesi, Süleyman Demirel Üniversitesi T1p Fakültesi Dergisi, 2006; 13(3):21-24

5. Friedman T.L. Geciktiğin için teşekkür ederim: Çılgıncasına hızlı bir çağda ayakta kalma rehberi. (Ed. Gülşen Heper; Çeviren: Zafer Akın). İstanbul: Boyner Yayınları, 2018.

6. Karasar N. (2015). Bilimsel araştırma yöntemi. Ankara: Nobel Akademik Yayınları,2015.

7. Erkuş A. Davranış bilimleri için bilimsel araştırma süreci. Ankara: Seçkin, 2011.

8. Fraenkel J. R. \& Wallen, N. E. How to design and evaluate research in education. New York:McGraw-Hill Higher Education, 2009. 
9. Christensen L.B., Johnson, R. B. ve Turner, L. A. Araştırma Yöntemleri: Desen ve Analiz. (Çeviri Ed.: Ahmet AYPAY). Ankara: Anı Yayıncılık, 2015.

10. Eraslan A. İlköğretim matematik öğretmen adaylarının 'Öğretmenlik Uygulaması' üzerine görüşleri. Necati Bey Eğitim Fakültesi Elektronik Fen ve Matematik Eğitimi Dergisi 2009; 3(1), 207-221.

11. Hançer Aydemir D. The Views of Vocational High School Students on Summer Internship:TheExample of Health
Services. Türk Yaşam Bilimleri Dergisi, 2016; 1 (1), 3442. Retrieved fromhttp://HYPERLINK"http://dergipark. gov.tr/tjls/issue/24143/256231" dergipark.gov.tr /tjls /issue /24143/256231

12. Tuygar Ş. F. Paramedik programı öğrencilerinin yaz stajı hakkındaki görüşlerinin incelenmesi. Düzce Üniversitesi Sağl1k Bilimleri Enstitüsü Dergisi, 2016; 6 (2), 92-100. Retrieved from http://HYPERLINK"http://dergipark.gov.tr/ duzcesbed/issue/24384/258500" dergipark.gov.tr/duzcesbed/ issue $/ 24384 / 258500$ 